\title{
Entrevista com Walter Carnielli
}

\author{
Lorenzzo Rodrigues Frade ${ }^{1}$
}

${ }^{1}$ Centro Universitário de Formiga (UNIFOR-MG)

Nesta edição, entrevistamos o professor, pesquisador e autor Dr. Walter Carnielli, professor de Lógica na Universidade Estadual de Campinas (Unicamp) e ex-diretor do Centro de Lógica, Epistemologia e História da Ciência (CLE).

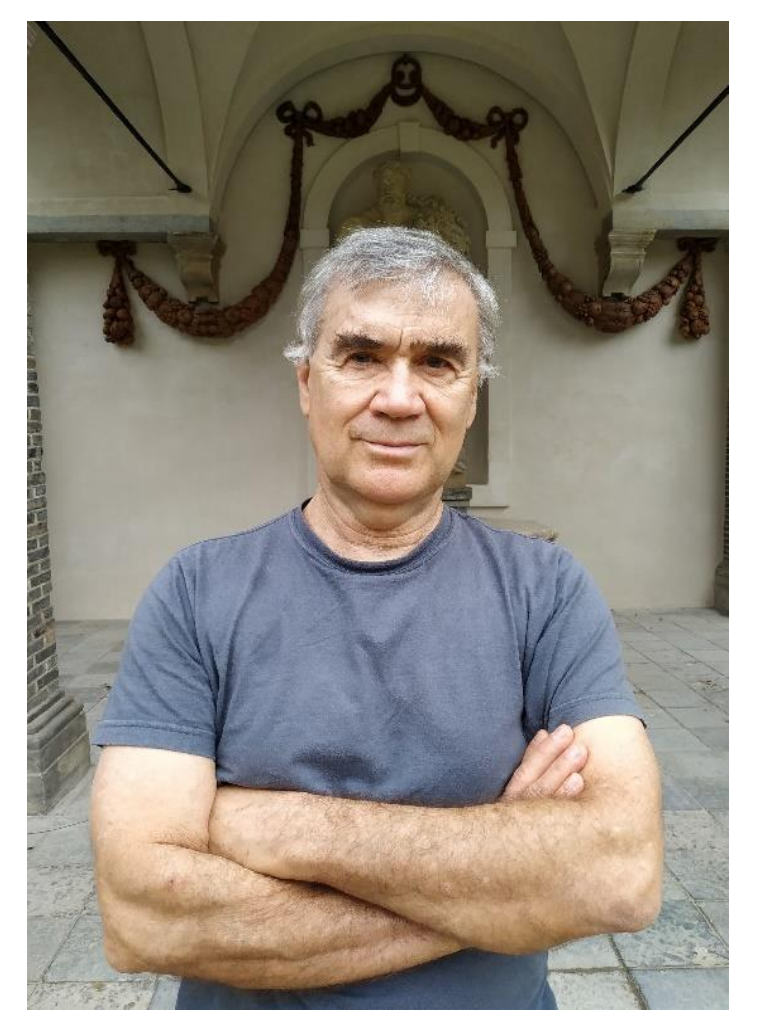

Graduado, mestre e doutor em matemática pela Unicamp, Walter Carnielli é professor de Lógica, no Departamento de Filosofia, da mesma instituição. Com importantes trabalhos tanto sobre resultados técnicos quanto sobre aspectos filosóficos da lógica, Carnielli é um dos pioneiros da escola brasileira de Lógica Paraconsistente. Membro de diversas sociedades científicas internacionais e do corpo editorial de diversas revistas científicas, nosso entrevistado foi também presidente da Sociedade Brasileira de Lógica por dois mandatos e fundou o GT de Lógica da Anpof (Associação Nacional de Pós-Graduação em Filosofia). Tem diversos livros publicados na área de Lógica e Filosofia da Lógica, bem como livros de divulgação para o público geral. Bolsista da Fundação Alexander von Humboldt, Carnielli recebeu diversas premiações nacionais e internacionais como a medalha de ouro da Telesio Galilei Academy of Science para 2013 e o terceiro lugar no Prêmio Jabuti de 2007, na categoria Melhor Livro de Ciências Exatas, Tecnologia e Informática. Em 2019 recebeu o prêmio CAPES de melhor Tese de Doutorado em Filosofia, junto com seu estudante Bruno Mendonça. Carnielli tem se interessado pela área de Inteligência Artificial, e é atualmente Vice-Presidente do Advanced Institute for Artificial Intelligence (AI2) e membro do Conselho Científico do Instituto Modal (Brasília). 
1) Embora seja matemático de formação, você atua na área de filosofia e leciona no Departamento de Filosofia da Unicamp. Para quem não é do ramo, a ligação entre as duas disciplinas nem sempre é clara. Em que medida sua formação como matemático contribui para sua carreira como filósofo? Como se dá a relação entre matemática e filosofia, em sua atuação profissional?

A relação entre matemática e filosofia é muito antiga, mas, muitas vezes, conflituosa. Originalmente não existiam cientistas ou matemáticos como os temos hoje, mas os chamados filósofos naturais. Os métodos dos filósofos naturais diferiam daqueles dos cientistas posteriores, principalmente a partir do século XVII, com Francis Bacon e Galileu. Os filósofos naturais não testavam suas ideias na prática, mas adotavam uma abordagem especulativa, típica da filosofia e da matemática, e confiavam na tradição e autoridade ao fazer suas declarações sobre o mundo natural.

Nas fortes ligações históricas entre matemática e filosofia, a lógica tinha um papel excepcionalmente importante, ao funcionar como uma ponte natural entre filosofia e matemática, e como guia da filosofia da matemática. A investigação profunda entre filosofia e matemática ajuda significativamente na compreensão de cada uma delas.

No meu caso particular, minha formação como matemático contribuiu para a carreira como filósofo (pelo menos como filósofo das ciências formais) em razão do meu interesse pelo infinito, pelos métodos racionais ligados ao infinito e pelas consequências do infinito na razão. Diversos dos meus trabalhos e artigos se dedicam a coisas desse tipo como, por exemplo, a investigação sobre problemas infinitos do tipo Ramsey inspirados em propriedades finitas. Esse estudo leva a um princípio novo que contradiz o Axioma da Escolha, chamado Princípio de Ariadne. Esse princípio, apesar de ser um rival do Axioma da Escolha, pode ser consistentemente adicionado aos axiomas da teoria dos conjuntos ZF sob certas condições. O Princípio de Ariadne, tomado como axioma, preserva todos os conteúdos finitos da matemática, mas se desvia do padrão nos conteúdos infinitos, e pode nos ajudar a entender a divisão finitoinfinito na matemática. Em outras palavras, o princípio mostra que vários princípios infinitos são possíveis, a partir do mesmo conteúdo finitário. Apesar de o estudo ter mais de 30 anos, publicamos um artigo recente que explica a questão em termos de jogos: "The Wonder of Colors and the Principle of Ariadne", em coautoria com Carlos Di Prisco, que aparece no livro "How Colours Matter to Philosophy" (Springer, 2017, editado por Marcos Silva, pp.309-317).

Esse trabalho é um típico resultado lógicomatemático com não somente inspiração filosófica, mas também com consequências filosóficas.
2) Ainda sobre seu percurso profissional, gostaríamos de saber quando você passou a se interessar pelos problemas filosóficos e quando começou a pensar na ideia de trabalhar em um departamento de filosofia. Você já se interessava por questões filosóficas desde a graduação ou esse interesse surgiu posteriormente?

Sempre me interessei pela dedução, pelos métodos de demonstração, pelo método axiomático, e pelo papel que a linguagem (formal e natural) desempenha em todo esse processo. Nunca vi uma grande distinção entre matemática e filosofia, sempre li muito, perguntava muito e, diferentemente da maior parte dos meus colegas matemáticos, interessava-me por línguas, cinema e literatura, ao lado da matemática. Lembro-me que um dos meus professores no curso de matemática da Unicamp sempre me sugeria, brincando (mas não muito), que eu "atravessasse a rua" e fosse fazer perguntas incômodas no Instituto de Filosofia (os dois institutos, de Matemática e Filosofia, são vizinhos na Unicamp). Depois de fazer Mestrado, Doutorado e PósDoutorado em Matemática, e de lecionar, por anos, disciplinas como Álgebra, Cálculo Integral, Análise, e Combinatória no Departamento de Matemática, resolvi, junto a colegas do grupo dos lógicos atuantes na Matemática, mudar para o Departamento de Filosofia em razão da atitude intolerante e preconceituosa dos dirigentes do Instituto de Matemática, pelos anos 90.

No Departamento de Filosofia, graças à nossa atuação conjunta no Centro de Lógica, Epistemologia e História da Ciência (CLE), um órgão independente mas historicamente ligado à Filosofia, meus colegas lógicos e eu pudemos trabalhar com liberdade, embora nem sempre em completa paz...

3) Em seu currículo, percebemos que a atuação docente sempre esteve presente. Você sempre pensou em seguir carreira acadêmica? Houve algum fator decisivo que lhe motivasse nessa escolha?

Resolvi seguir a carreira acadêmica porque queria pensar, e não ficar pendurado em horários estritos, dirigentes idiotas, colegas carreiristas e na falta de projetos das empresas brasileiras. Antes de entrar para a Universidade, trabalhei numa multinacional, e pude sentir o peso da atitude retrógrada e anti-intelectual, à época - nem quero imaginar como deve ser hoje.

4) A docência parece ser uma atividade que atrai cada vez menos jovens. Você tem algum conselho ou palavra de incentivo para o jovem que pensa em ser professor? 
Nunca gostei de lecionar. Sempre tive um suave desprezo por horários, planos, gestão educacional, e coisas desse tipo. Por outro lado, ensinar é uma das minhas paixões. Não confundo uma coisa com outra. Ser "professor" nunca bastou para mim - sempre pretendi ensinar a pensar, ensinar os jovens a criar, imaginar, a serem cientistas. E posso dizer que tive bastante sucesso: tive estudantes e orientados excepcionais, que hoje ocupam postos de destaque na ciência, não só nacional. Nem vou mencioná-los, porque ocuparia um grande espaço nesta entrevista.

5) E sobre a produção acadêmica - qual o seu segredo para produzir tanto material de qualidade? Daria alguma dica para o leitor?

Penso que as grandes chaves do sucesso para se ter uma produção acadêmica de destaque sejam: primeiro, inspirar-se em figuras de real destaque, evitando admirar imbecis (penso que não preciso dar nomes, temos alguns em destaque na mídia e em altos cargos políticos) e, segundo, gostar de compreender coisas interessantes, seja a gramática da língua Tupi, as ideias econômicas da mais-valia de Karl Marx ou a teoria de matroides e, mais que tudo, gostar de resolver problemas. Essa é a minha receita.

6) Você possui prêmios, colaborações e atuações profissionais em quase uma dúzia de países. Conte-nos um pouco sobre sua trajetória no exterior: quais as maiores dificuldades? $O$ que o brasileiro pode esperar, ao pesquisar nos países em que você trabalhou?

Estudei e trabalhei no Chile, Estados Unidos, Itália, França, Luxemburgo, Alemanha e Portugal, além de períodos menores na Venezuela, Argentina, Polônia e Espanha. Nunca tive grandes dificuldade, muito em razão de meu interesse pelas línguas e pela cultura. Nunca achei aborrecido ou entediante aprender línguas, por exemplo: aprendi espanhol em dois meses, alemão bastante fluente em três meses e, em duas semanas na Polônia ou na Turquia já conseguia articular algumas sentenças. Não se trata de nenhuma capacidade superior, apenas acho isso fascinante, como acho aborrecido assistir esportes. A grande dificuldade é agir como as pessoas locais, prestar atenção àquilo que para eles é importante, como ter uma agenda organizada, cumprir horários, seguir as normas locais, etc. Feito isso, há poucos problemas. Do ponto de vista do trabalho científico, o essencial é ter resultados que interessem aos colegas estrangeiros. Isso se consegue com muita dedicação, uma atitude arrojada e um pouco de sorte.

7) No ramo da filosofia, por vezes somos questionados sobre quais as contribuições práticas da disciplina para o cidadão comum. Você tem um livro, em coautoria com Richard L. Epstein, chamado "Pensamento Crítico: o poder da lógica e da argumentação". Podemos dizer que a lógica aplicada à argumentação é uma das contribuições mais significativas da filosofia para os nãofilósofos? Conte-nos um pouco sobre a importância da lógica e da argumentação para o público geral.

A lógica informal aplicada à teoria da argumentação é de fato uma grande contribuição ao pensamento racional. Filosofar é basicamente argumentar, e a lógica usada no pensamento crítico opera no nível da linguagem natural. A partir daí o estudante amadurece para compreender a linguagem simbólica da lógica formal, e argumentos filosóficos sofisticados como o Cogito de Descartes, ou a Apologia de Sócrates.

Mas para o público geral, noções de argumentação são vitais. Só assim se consegue uma defesa contra teorias conspiratórias como a Terra plana, ou contra a ideia de que a atividade humana não é responsável pelas mudanças climáticas. As falsas "teorias" da Terra plana podem ser refutadas pela simples trigonometria ou por leis físicas básicas, mas as pessoas precisam aprender como montar seus argumentos. Outro aspecto fundamental, hoje, diz respeito a como se defender das "fake news". A recente quarta edição de "Pensamento Crítico: o poder da lógica e da argumentação" (Editora Rideel, 2019) traz um capítulo dedicado a isso, que nada mais é que uma compilação dos grandes pilares da argumentação particularizados contra os abusos das mídias sociais.

8) Ainda sobre aplicações práticas da filosofia, é sabido que você e outros filósofos brasileiros possuem papel central no desenvolvimento de lógicas paraconsistentes. Poderia discorrer sobre algumas aplicações práticas da Lógica Paraconsistente?

Contradições ocorrem com frequência na vida cotidiana. Muitas vezes, descobrimos que temos crenças inconsistentes ou fazemos reivindicações inconsistentes, e sempre estamos sujeitos a informações contraditórias. Dessa forma, o cuidado em identificar contradições e evitar a explosão trivializante passa a ser altamente relevante em bancos de dados, na análise do discurso, na medicina por evidência, nos "Big Data", etc. Recentemente, contamos 70 cientistas estrangeiros fora dos círculos filosóficos conhecidos propondo aplicações da Lógica Paraconsistente em linguística, engenharia, computação, aprendizado de máquinas, física quântica e probabilidades, entre outros campos. 
9) Você vê na lógica algum papel especial dentro da filosofia? Conte-nos um pouco sobre o que mais lhe fascina na área.

$\mathrm{Na}$ minha opinião, e isso é um tema central na minha investigação, a lógica no sentido mais amplo é uma ferramenta da razão. Dentro dessa perspectiva, fica claro o papel da lógica na filosofia. Quando estudamos lógicas multivalentes, lógicas difusas, lógicas paraconsistentes, novas teorias de probabilidade baseadas nessas lógicas, novos métodos de prova para essas lógicas, ou novos paradigmas de argumentação baseadas em lógicas alternativas, estamos investindo em nosso arsenal de métodos racionais.

10) Você tem alguma perspectiva sobre o futuro da filosofia e da lógica no Brasil? Quais as tendências? O que esperar? E o que fazer para construir um bom futuro?

O futuro da filosofia, da lógica e das humanidades no Brasil, infelizmente, é desesperador. Numa sociedade que não vê alternativa que escolher governantes que odeiam o conhecimento, que desprezam a racionalidade em favor de discursos feitos para agradar seu séquito de seguidores, que não se preocupam em dividir o país, não há lugar para o pensamento esclarecido. O reflexo disso se vê na política de corte de financiamento à pesquisa, no desmonte dos órgãos de fomento e no apoio a crenças religiosas obscurantistas. Estamos penetrando na Idade das Trevas difundidas pelo Twitter, Instagram, YouTube e Facebook. Resta à lógica e à filosofia o papel da resistência. 